University of Washington Tacoma

UW Tacoma Digital Commons

Social Work \& Criminal Justice Publications

Social Work \& Criminal Justice

2018

\title{
Voluntary Placements in Child Welfare: A Comparative Analysis of State Statutes
}

Annette Semanchin Jones

JaeRan Kim

University of Washington Tacoma, kimjr@uw.edu

K. Hill

J.Diebold

Follow this and additional works at: https://digitalcommons.tacoma.uw.edu/socialwork_pub

\section{Recommended Citation}

Semanchin Jones, Annette; Kim, JaeRan; Hill, K.; and Diebold, J., "Voluntary Placements in Child Welfare: A Comparative Analysis of State Statutes" (2018). Social Work \& Criminal Justice Publications. 485.

https://digitalcommons.tacoma.uw.edu/socialwork_pub/485 
Title: Voluntary Placements in Child Welfare: A Comparative Analysis of State Statutes

First and Corresponding Author:

Annette Semanchin Jones, Ph.D., MSW

Assistant Professor

University at Buffalo School of Social Work

662 Baldy Hall

Buffalo, NY 14260

(716) 645-1862

amsemanc@,buffalo.edu

Second Author:

JaeRan Kim, PhD., LISW

Assistant Professor, Social Work and Criminal Justice

University of Washington Tacoma

Box 358425, 1900 Commerce Street

Tacoma, WA 98402-3100

Phone: (253) 692-5623

kimir@uw.edu

Third Author:

Katharine Hill, PhD, MSW, MPP, LISW

Associate Professor

St. Catherine University - University of St. Thomas School of Social Work

SCB \#201

2115 Summit Avenue

St. Paul, MN 55105

Phone: 651-962-5809|

Katharine.Hill@stthomas.edu

\section{Fourth Author:}

Josal Diebold, Doctoral Student

University at Buffalo School of Social Work

219 Parker Hall

Buffalo, NY 14214

josaldie@buffalo.edu 
Voluntary Placements in Child Welfare: A Comparative Analysis of State Statutes

\section{Introduction}

Children typically enter out of home placement in the child welfare system following an investigation by child protective service workers that identifies substantiated abuse and/or neglect by the child's caretakers. In these cases, there is judicial involvement that leads to the child being removed from their caretakers' home and placed into a foster care setting or residential placement. A smaller proportion of children and youth enter foster care placement through a voluntary placement. Unfortunately, data on voluntary placements are less than robust, making the rate at which they occur difficult to ascertain. However, in her study using national Adoption and Foster Care Statistics (AFCARS) data, Hill (2017) found that 3.4\% of outof-home placements were voluntary. Notably, though, countries in Europe frequently place children using voluntary placements; in Finland and Denmark, between $80 \%$ and $90 \%$ of placements are voluntary, and in Sweden the rate is close to $70 \%$ (Gilbert, 2012). As such, the use of voluntary placement in the U.S. appears to stand in stark contrast to policies seen in other developed countries.

Voluntary placements occur when a child's caretakers voluntarily come to an agreement with the child welfare authority to place their child outside of their family home; this is often referred to as a voluntary placement agreement (Hill, 2017). As per federal law, the details of placement are mutually decided and judicial determination is only required if the placement exceeds 180 days (Social Security Act of 1935, 2010). According to the federal guidelines, caretakers do not have to give up their legal custody when placing their child(ren) in a voluntary placement (Gruttadaro, 2014). 
Extant literature indicates that children's behavioral, medical, and mental health needs, as well as developmental disabilities, are catalysts for some voluntary placements (Cohen, Harris, Gottlieb, \& Best, 1993; Friesen, Giliberti, Katz-Leavy, Osher, \& Pullmann, 2003; NAMI Minnesota, 2009). Other factors, such as parental stress, lack of resources, and shortage of social supports, also facilitate caretakers' decision to voluntarily place their children in foster care (Bromley \& Blacher, 1991; Jones, 1998). The intended outcome for a voluntary placement agreement, though varied as per reason for placement, is a temporary means for meeting the needs of the family and child, without requiring relinquishment (Cohen, et al., 1993).

Little is known about the characteristics and experiences of children and youth who are placed in foster care through a voluntary placement. While previous studies have surveyed states' child welfare directors (GAO, 2003) or families who have used voluntary placements (Friesen et al., 2003), there has not been an analysis of state legislation around voluntary placements that do not require legal custody transfer. However, the previous literature does suggest that there is considerable variation among states in how they understand and implement voluntary placements. The purpose of this study was to explore how states legislate voluntary placement. For this content analysis, we analyzed the statutes on voluntary placements for all 50 states and Washington D.C., examining factors such as definitions, timelines, and process for court involvement. In the subsequent section, we first outline federal guidelines and existing literature on voluntary placements in child welfare.

\section{Legislation on Voluntary Placements}

Voluntary foster placement is outlined in federal child welfare legislation within Title IVE of the Social Security Act. Section 672, in particular, describes voluntary foster placement as an out-of-home placement that is entered into by a "parent or legal guardian of the child," who 
seeks out an agency's services and enters into an agreement with the agency (Social Security Act, 2010). This section of the Act states that children who are removed from their parent's care under these circumstances are eligible to receive foster care maintenance payments. Section 672(e) of the same Title states that

"No Federal payment may be made under this part with respect to amounts expended by any State as foster care maintenance payments under this section, in the case of any child who was removed from his or her home pursuant to a voluntary placement agreement as described in subsection (a) and has remained in voluntary placement for a period in excess of 180 days, unless there has been a judicial determination by a court of competent jurisdiction (within the first 180 days of such placement) to the effect that such placement is in the best interests of the child."

This indicates that federal statutes place some constraints on how long Title IV-E funds may used for voluntary placements. However, within these broad federal guidelines, states are allowed much flexibility to interpret and establish their own procedures and policies for voluntary foster placements, such as by adding additional regulations around judicial hearings, providing different types of placements, or requiring a transfer of custody. So, states may use the terminology of voluntary placement to signify a placement in which caretakers do, in fact, have to surrender their legal rights and relinquish (Friesen et al., 2003). In addition, extant literature prominently uses 'voluntary' in relation to kinship care, yet not all voluntary placements include kin (Berrick \& Hernandez, 2016). Consequently, definitional clarity and procedural consistency around voluntary placements appears to be significantly lacking.

\section{Types of Voluntary Placement}

\subsection{Voluntary kinship care.}

In the federal statutes, voluntary placements are understood to be agreements between caretakers and agencies that are time-limited. The same terminology ('voluntary placement') has been used in the literature in relation to particular types of foster care placements, such as 
kinship care. Kinship care involves the placement of a child with a family member, rather than a non-related foster family or care facility. Multiple forms of kinship care exist, varying in terms of state involvement and custody transfer, but remaining consistent in terms of placement with family (Berrick \& Hernandez, 2016). In some cases, the family has come to the attention of the child welfare system, and voluntary placement with a relative has been offered as an alternative to the traditional foster care system, a process sometimes referred to as kinship diversion (Berrick \& Hernandez, 2016; Wallace \& Lee, 2013). Vericker, Kuehn, and Capps (2007) also referred to this type of voluntary kinship care for children of immigrants, in which case child welfare was involved but did not take legal custody. Scholars have stressed the lack of information and documentation on voluntary kinship placement, highlighting a clear gap in current research (Berrick \& Hernandez, 2016; Wallace \& Lee, 2013). For this study, we focused only on voluntary placements that are meant to be temporary and in which there is no transfer of legal custody.

\subsection{Voluntary Relinquishment.}

In addition to ambiguity around voluntary kinship care, the boundaries defining voluntary placement and voluntary relinquishment are also obscured, particularly due to differences in state implementation (Cohen, Harris, Gottlieb, \& Best, 1991). There are a number of factors and areas contributing to the complexity and confusion surrounding voluntary relinquishment versus placement. First, voluntary placement, as understood in the current study, does not require loss of legal custody by parents or guardians, whereas voluntary relinquishment does. In some states, the voluntary transfer of custody is the only way through which parents are able to attain supports for their children's behavioral, medical, or mental health needs (Friesen et al., 2003; GAO, 2003). 
Second, the lack of explicit statutes and policies on voluntary placements was found to be a significant catalyst for parents choosing voluntary relinquishment (Cohen et al., 1991). In this vein, Benner (2009) pointed out the problematic nature of voluntary, but permanent, termination, rather than voluntary and temporary placement. Moreover, Hill (2017) found that relinquishment was the most commonly identified reason children were voluntarily placed. On the other hand, the author also highlighted the confusing nature of relinquishments' association with voluntary placement, thereby highlighting further confusion in policy and practice (Hill, 2017).

Finally, "safe haven" laws fall under voluntary relinquishments, as they allow for the legal, voluntary abandonment of infants, by parents, at designated locations (Sanger, 2006). The intersecting usage of voluntary placements and voluntary relinquishment obfuscates whether parents are required to surrender their rights in order to place their child in care. Voluntary relinquishment is beyond the scope of the current study, but we did note which states have specific policies on voluntary relinquishment of parental rights.

\subsection{Extended Foster Care.}

Another type of voluntary placement is the voluntary extension of care for youth in placement prior to the age of 18 . Whereas prior laws mandated that youth exit foster care at the age of 18, current policies, such as Foster Care Independence Act of 1999 (P.L. 106-169) and the Fostering Connections to Success and Increasing Adoptions Act of 2008 (P.L.110-351), allow states to provide extended foster care to better support youth past 18 years of age to assist with housing, health insurance, education, and employment (Child Welfare Information Gateway, 2017). Lee, Courtney, and Tajima (2014) found that extended foster care resulted in more favorable outcomes for young adults, particularly reduced involvement with the criminal justice 
system. Though federal legislation has provided states funding to offer extended care, not all states have made this extended care available to youth in their state (Bass, Shields, \& Behrman, 2004). Moreover, participation in extended care is not typically required, thereby presenting yet another conceptualization of voluntary involvement in foster care. Young adults can elect whether to utilize supports and resources of extending their time in care, with the goal of aiding their eventual transition (Child Welfare Information Gateway, 2017). Though extended care is, by nature, voluntary, it is outside the scope of this study and is distinct from the voluntary placement described in federal guidelines.

\section{Factors Influencing Voluntary Placement}

Hill (2017) found differences between voluntarily placed youth and court-ordered youth, particularly in terms of age, ethnicity, reason for placement, placement length, placement type, and style of discharge. For example, children placed via a voluntary placement agreement were more likely to have a disability, to be placed in supervised independent living or group homes rather than foster homes, and to leave the foster care system by emancipation, running away, or going to a different agency (Hill, 2017). Notably, the differential outcomes, like placement length and style of discharge, between voluntary and court-ordered placements may be due in part to differential inputs, such as the reasons for placement. Hill's (2017) findings support previous research that suggests voluntary placements are used in order to access medical, behavioral, and mental health services. A 2003 United States General Accounting Office (GAO) report found 12,700 children were placed into the child welfare or juvenile justice systems for the sole purpose of receiving mental health services. However, the report also highlighted the inconsistencies across states in terms of requiring parents to give up legal custody (GAO, 2003). 
Families who seek out-of-home care for their children with disabilities are significantly impacted by daily stressors of responding to the ongoing, complex needs of their children, as well as a lack of financial and social support in meeting those needs (Bromley \& Blacher, 1991; GAO, 2003). While some research indicates that families with greater financial needs experience higher levels of child behavior problems (McConnell, Savage, \& Breitkreuz, 2014), other research has found that regardless of the family's income, many families of children with significant mental health and behavioral diagnoses struggle to meet the children's needs as well as other family, community, and job commitments (GAO, 2003; Rosenzwig \& Brennan, 2008).

Services for children and youth with mental health diagnoses come through a number of different systems, including both private and public health insurers, child welfare, juvenile justice, education and special education, residential treatment centers and community based services(GAO, 2003; Mechanic, McAlpine, \& Rochefort, 2014). Bringewatt and Gershoff (2010) critiqued the current system as a "patchwork of policies that developed in areas outside of mental health, such as the education, child welfare, and juvenile justice systems" (p.1292). They, and other advocates and researchers, have indicated that the lack of communication among systems, the number of systems, underfunding, and health insurance parity are all critical issues in accessing adequate mental health services for families, regardless of their socioeconomic status (Mechanic, McAlpline, \& Rochefort, 2014; Rosenzweig \& Brennan, 2008). Costs associated with mental health treatment, whether inpatient or outpatient, can be very high, raising issues of accessibility to services for children (GAO, 2003).

Much of the literature on why families voluntarily place their children centers on the role of the child's special needs (i.e., disabilities and mental illness). Still, less is understood about the role social and economic factors generally play in the decision of families to voluntarily 
place. Just as families with children with disabilities struggle with financial and emotional burdens, families in child welfare, in general, are more likely to contend with significant burdens such as addiction, unemployment, and housing instability (Jones, 1998; McConnell, Savage, \& Breitkreuz, 2014). In terms of kinship care, Gleeson, Wesley, Ellis, Seryak, Talley, and Robinson (2009) identified parental incarceration, illness, death, and substance abuse as driving forces behind the placement of the child with a relative. In addition, families involved in kinship placements were often of lower socioeconomic status, with reduced access to needed supports and resources (Cuddeback, 2004). Although family characteristics, such as poverty, substance abuse, and social support, may play a role in families' decisions around voluntary placement, little of the current literature on voluntary placements explores such factors.

Due to overlapping and unclear terminology throughout the state policies, there remains ambiguity surrounding the implications and nuances in implementing statutes on voluntary placements. This current study provides an overview of existing statutory language about voluntary foster care and placement agreements in order to determine the current status of state guidance on this issue. The research question for this study is: What are the existing state-level and Washington D.C. statutes that pertain to voluntary placements?

\section{Methods}

For this study, we conducted a content analysis of statutes (for all 50 states and D.C.) containing references to voluntary foster care placements. Hsieh and Shannon (2005) described content analysis in social science research as "...a research method for the subjective interpretation of the content of text data through the systematic classification process of coding and identifying themes or patterns" (p.1278). Content analysis of state statutory language has been used by legal scholars (Sliva \& Lambert, 2015), as well as by child welfare researchers 
(Lightfoot, Hill, \& LaLiberte, 2010). The purpose of this study was to examine the content of legislation on voluntary foster care. The content analysis used in this study was a directed approach (Hsieh \& Shannon, 2005), using a priori codes to categorize elements of the statutes addressing voluntary placements, including ways of defining voluntary placements and process and implementation guidelines included in the statutes. This method was selected because of the limited research literature on the topic, with the aim of extending current understanding of this issue (Hsieh \& Shannon, 2005).

\subsection{Data Collection}

\subsubsection{Sampling Procedures.}

We used the Westlaw Campus database and Google to search state statutes related to voluntary foster care placements. Westlaw Campus contains full text of state regulations and statutes, as well as additional administrative materials. Within Westlaw Campus each state and the District of Columbia was searched, using the search terms: "voluntary foster care", "voluntary foster care placement", "voluntary placement", and "voluntary relinquishment." After the search terms were entered, we reviewed the results to ensure that the content was pertinent to the research question, and met the following criteria: 1) included statutory language related to voluntary foster care placements (with some oversight by the state child welfare systems); and 2) included voluntary placements in which parents retained legal custody. Because voluntary placements are not clearly defined in the literature, we excluded statutes that initially appeared to be related to voluntary foster care placements, but addressed a different issue. Examples of statutes that were excluded from analysis included the following: statutes that only addressed voluntary relinquishments in which parents surrender legal custody (including safe haven laws); statutes that only addressed extending care of youth between the 
ages of 18 to 21 ; and statutes that addressed other voluntary placements in juvenile detention facilities. Additionally, documents were excluded at this point if, upon preliminary review, it was determined that the document was administrative regulations rather than a statute, or if the document was referring to policy at the county level rather than state level.

After the Westlaw Campus search was completed, we did a second search using Google and the same search terms listed above. In this step, the search terms were paired with each state's name (so, for example, "Alabama" and "voluntary foster care"). This second search was to identify any missed or overlooked content related to state statute. If any additional language was identified, it was added to the relevant state's section in the electronic file. The documents were checked for duplication, and duplicates were removed. The final document included the statutory language for each state; there were 51 in total (50 states and the District of Columbia).

\subsubsection{Coding}

For the coding scheme in this study, we developed a coding rubric to ensure the systematic recording of the data. The items included in the rubric examined several elements of statutes on voluntary placements. The rubric contained eleven dichotomous variables that we coded as "Yes or No/Not Included." Based on a preliminary reading of the statutes, we included a priori codes for some items, and we also included qualitative notes and memos for several items in the rubric. See Table 1 for a list of those items. Although we noted whether states included regulatory or administrative guidance on voluntary placements, we did not include those guidelines in the remainder of the analysis.

Table 1. Items on the rubric for analysis of statutes related to voluntary foster care placements.

Type of Item Item on Rubric 
Yes or No/Not Included

A Priori Codes

Open-ended Items

\& Qualitative Memos
Guidance on VP

Definition of VP

Description of VP

Federal Guidelines referred to

Amendments made after initial legislation passed

Court Involvement required

More than one type voluntary placement

Placement for treatment - specifically addressed

Parents retain legal custody

Parents retain authority for decisions

Timelines: 180 days, 90 days, other, not included

Process for placement: Agreement, other, not included

Agency responsible for placement: Child Welfare, Children's Mental

Health, Disability Services, Juvenile Justice, other, not included

Process for ending placement: Parents decision, agency decision, other, not included

Financial responsibility for placement: Parent, child welfare agency, both, other, not included

Actual definition or description

List other supporting state-level guidance

Year statute was enacted

List other specific types of types of voluntary placements

Parental authority limitations or guidelines

Any item for which "other" was marked in a priori codes

Researcher memo and general notes for each state

We first pilot tested the rubric by randomly selecting three states, which were then all coded by three researchers on the research team. We met and reviewed each item coded until consensus was reached. Minor changes were made to the rubric to assist with clarity of coding, but no content changes were made. All remaining statutes were then coded independently by the three researchers, with regular meetings to discuss and resolve any discrepancies in the coding process. For statutes where questions or disagreement remained, the fourth author coded those statutes independently. This occurred for three of the states. The research team then met a final time to reach consensus on the coding of these states. All of the finalized codes were entered into a master copy of the rubric, which was used for the data analysis. 


\subsection{Data Analysis}

Descriptive statistics were used to summarize the quantitative data gathered in the coding process, including frequency counts and percentages. These descriptive statistics allowed us to compare key elements of the statutes across all 50 states and Washington D.C. In addition to the quantitatively coded categories, several of the open-ended categories were further analyzed to identify important patterns and themes. Specifically, the categories 'actual definition or description,' items for which the 'other' category was marked, and 'researcher memo and general notes for each state' included additional qualitative data that the research team reviewed. For the definition and description category, we used open coding to identify any patterns in how states defined voluntary placements and how much detail was included in the definition itself (Patton, 2002). For the “other" categories of 'funding,' 'timelines,' and 'process for ending,' we also used this same open coding process to identify themes for each factor.

For the qualitative memos, we used an open coding process to identify themes across statutes in how they regulated voluntary placements. In this comparative process, we also sought to identify any unique cases in which a statute addressed the regulation of voluntary placement in a very distinctive manner. Because there is so little literature on voluntary placements, we felt it was important to provide both common themes and unique cases in order to build understanding of this topic and to understand the breadth of approaches by states (Patton, 2002). Two of the researchers independently coded the memos, and then they met to discuss the themes and preliminary findings until consensus was reached to create a final set of key themes and findings.

\section{Findings}

The findings of the statutory analysis are first organized in a summary table that outlines key elements of voluntary placements (See Table 2 for the major variables from the analysis of 
voluntary placement statutes.). This summary table is followed by additional details about how states refer to Federal guidelines, the overall processes that are outlined by statute, and an outline of findings about varying types of placements noted in the statutes.

Table 2. Major variables from rubric

\begin{tabular}{|c|c|c|}
\hline Variable & $\begin{array}{c}\text { Frequency } \\
(\%)\end{array}$ & States/D.C. \\
\hline & & All states and D.C. $(N=51)$ \\
\hline \multicolumn{3}{|l|}{ Statute on VP } \\
\hline Yes & $40(78.4 \%)$ & $\begin{array}{l}\text { AK AZ CA CO CT FL GA HI ID IL IN IA KY LA ME MD MA } \\
\text { MI MN MO MT NE NV NJ NM NY NC ND OH OK OR PA RI } \\
\text { TN TX VA WA WV WI DC }\end{array}$ \\
\hline No & $11(21.6 \%)$ & AL AR DE KS MS NH SC SD UT VT WY \\
\hline \multicolumn{3}{|l|}{ Guidance on VP } \\
\hline Yes & $39(76.5 \%)$ & $\begin{array}{l}\text { AL AK AZ CA CO CT FL GA ID IL IA KY ME MD MA MI MN } \\
\text { MS MO MT NE NJ NM NY NC ND OH OR PA RI SC TN TX } \\
\text { UT VT VA WAWV WI }\end{array}$ \\
\hline No & $12(23.5 \%)$ & AR DE HI IN KS LA NV NH OK SD WY DC \\
\hline \multicolumn{3}{|l|}{ Statute or Guidance } \\
\hline Yes & $45(88.2 \%)$ & $\begin{array}{l}\text { AL AK AZ CA CO CT FL GA HI ID IL IN IA KY LA ME MD } \\
\text { MA MI MN MS MO MT NE NV NJ NM NY NC ND OH OK } \\
\text { OR PA RI SC TN TX UT VT VA WA WV WI DC }\end{array}$ \\
\hline No & $6(11.8 \%)$ & AR DE KS NH SD WY \\
\hline
\end{tabular}

Only states and D.C. with voluntary placement statutes $(n=40)$

Definition of VP

Yes $\quad 9(22.5 \%) \quad$ CA IA MD MN MO NE NY OR TX

No $\quad 31(77.5 \%) \quad$ AK AZ CO CT FL GA HI ID IL IN KY LA ME MA MI MT NV NJ NM NC ND OH OK PA RI TN VA WA WV WI DC

Court Involvement Required for Initial Placement Yes $\quad 5(12.5 \%) \quad$ IA LA NJ VA WV

No \& $\quad 35(87.5 \%) \quad$ AK AZ CA CO CT FL GA HI ID IL IN KY ME MD MA MI 
Not Included

Process for Placement

Agreement

$29(72.5 \%)$

AK AZ CA CO GA HI ID IL IN IA KY LA ME MD MN MO MT NV NJ NC OH OR PA TN TX WA WV WI DC

Other $\quad 5(12.5 \%) \quad$ CT NM NY OK VA

Not included $\quad 6(15.0 \%) \quad$ FL MA MI NE ND RI

Timelines for Placement Length and Court Review

Zero days $\quad 1(2.5 \%) \quad$ IA

10 days $\quad 1(2.5 \%) \quad$ LA

30 days $\quad 5(12.5 \%) \quad$ MD MT NY OH PA

60 days $\quad 3(7.5 \%) \quad$ NJ VA WA

90 days $\quad 5(12.5 \%) \quad$ AZ HI NC OK WV

120 days $\quad 2(5.0 \%) \quad$ CT RI

180 days $\quad 9(22.5 \%) \quad$ AK ID ME MA MN NV NM OR WI

Not included $14(35.0 \%) \quad$ CA CO FL GAIL IN KY MI MO NE ND TN TX DC

Out of the 50 states and Washington, D.C., 40 (78.4\%) had a statute mentioning voluntary placement, and the remaining $11(21.6 \%)$ did not. Likewise, the majority of states (76.5\%) had some non-statute guidance (i.e., regulatory code or policy handbook) on voluntary placement, whereas $23.5 \%$ did not. For the purpose of this exploratory study, we only included information from statutes for the analyses, although several states provided more procedural details in other documents. For example, South Carolina did not have any statutory references to voluntary placement, but the state's Human Services Policies and Procedures Manual did include relevant information in the foster care chapter. The manual defined voluntary placement, referred to the federal statute on voluntary placements, and included steps to be taken to 
voluntarily place a child. Only six states had neither a statute nor other types of guidance referring to voluntary placements (Arkansas, Delaware, Kansas, New Hampshire, South Dakota, and Wyoming).

Of the 40 statutes focused on voluntary placement for foster care, only 8 included a specific definition in the statute. As an example, Iowa's statute stated, "'Voluntary placement' means a foster care placement in which the department provides foster care services to a child according to a signed placement agreement between the department and the child's parent or guardian."

Additionally, there were varying amounts of information included in the statutes ranging from no details to many details. In fact, $20(50.0 \%)$ of the statutes that mentioned voluntary placements included few to no details. For example, in Louisiana, voluntary placement was mentioned only once in a statute on local citizen review boards and did not include a definition, description, or any other details on procedures for placement. Another $13(32.5 \%)$ statutes contained language and provisions on voluntary placements, but they did not include much description. Additionally, in some cases, the statutes used different terms for voluntary placement (i.e., 'temporary custody' in Ohio and 'parental child safety placement agreement' in Texas) and others only detailed certain types of placements (i.e., only treatment specific). Conversely, 7 (17.5\%) statutes were more detailed, such as Minnesota, which included information on more than one type of voluntary placement - both disability related and nondisability related. See Table 3 below for a complete list of each category.

Table 3. Categorization of states \& D.C. by level of detail and clarity on voluntary placement statute $(n=40)$.

\begin{tabular}{llc}
\multicolumn{1}{c}{ Level of detail } & Frequency (\%) & States \\
\hline Detailed to Very Detailed & $7(17.5 \%)$ & AZ ME MD MN NY OK OR
\end{tabular}


Lacking Clarity (includes ambiguous meanings, different language, or only referring to certain types of VP)

Not Detailed
CA CO CT HI ID IA KY NE OH PA RI

TX WA

\subsection{Federal Guidelines}

$20(50.0 \%)$

AK FL GA IL IN LA MA MI MO MT NV

NJ NM NC ND TN VA WV WI DC

Although the majority of statutes (84\%) did not explicitly refer to the federal guidelines, many of them appeared to use language and structure similar to the federal statute, as is noted in subsequent sections. In addition, while the federal guideline on voluntary placements was enacted in 1980, the first year that statutes were enacted regarding voluntary placements ranged from 1954 to 2015, and the year of the most recent amendment varied from 1983 to 2017.

\subsection{Placement Process, Courts, and Timelines}

In most cases, a written agreement was the mechanism used for placing a child into a voluntary placement (72.5\%), as the federal guidelines also include. Language on placement agreements varied from a mere mention to more detailed descriptions. For example, Oregon's statute was very detailed, explicitly including multiple details for placement agreements, such as the obligations and authority of parents and guardians, the child, and the agency while the child is in the voluntary placement. Additionally, the majority of statutes either did not initially require court involvement for voluntary placements or did not mention court involvement at the time of placement $(87.5 \%)$. Of the 40 statutes mentioning voluntary placement, $14(35.0 \%)$ did not include any timelines limiting or constraining voluntary placements. The remaining statutes had timelines regarding length of placements or required court involvement; the timing of court procedures ranged from zero days (i.e., court involvement is required at time of placement) to 180 days of placement (which matches the federal guidelines). For instance, Iowa had a "zeroday" timeline in which courts must review the case before a voluntary placement begins, 
whereas in Hawaii, the statute stated that families have three months (90 days) from the date of placement to complete the service plan before a petition is filed in court. In statutes such as these, the explicit timelines indicate that the term "voluntary" may be a slight misnomer inasmuch as the placement may shift from voluntary to court-mandated if the service plan is not completed. Few statutes were explicit in regard to parents' legal custody or authority to make decisions while their child is in a voluntary placement. Kentucky, on the other hand, is an example of a statute that explicitly stated that "any parent, guardian, or other person having legal custody of a child who has consented to the child's voluntary commitment to the cabinet shall be entitled to participate in treatment planning for the child..."

The process for ending a placement was noted in just over half the statutes $(n=22)$, and included information on the role of parents, youth, agencies, and courts. For one statute (2.5\%), it was only listed that parents had the right to end placement, without mention of the child welfare agency or court. Three more statutes (7.5\%) included parents' right to end the placement, as well as time limits on placements, and seven (17.5\%) listed parents and agencies as able to end placements. One (2.5\%) statute listed parents and courts as having authority to end placement, another one (2.5\%) named parents, the youth, or the courts, and the remaining four $(10.0 \%)$ named parents, the agency, or the courts. As an example, in Montana, any involved party (parent, agency, court) has the authority to end the voluntary placement, whereas in New Mexico, the statute only mentioned terminating the placement after a time limit of 365 days within a two-year span. The federal statute specifies that the placement can be ended by parents or guardians unless the agency opposes the decision and "obtains a judicial determination" (Social Security Act of 1935, 2010).

\subsection{Types of Voluntary Placements}


The current study focused specifically on temporary voluntary placements for children and youth in child welfare, but multiple statutes mentioned other types of placements, including: relinquishment for adoption, safe haven, and voluntary surrender (45.0\%); juvenile justicerelated placements $(10.0 \%)$; or extended foster care up to age $21(25.0 \%)$. In several cases, states had more than one type of voluntary placement, other than traditional child welfare. Eleven $(27.5 \%)$ statutes included a specific focus on voluntary placements to help meet the treatment needs of children with disabilities or mental health disorders. For some of these placements, multiple state departments had authority, including children's mental health or disability services. (See Table 4 for examples of states that focus on voluntary placement for treatment.)

Table 4. Treatment-specific Voluntary Placements

\begin{tabular}{ll}
\hline Type of Treatment & State \\
\hline Mental Health & CT ID IN KY MD MO OR RI \\
Disability & CT IN IA MD MN OR RI WA \\
$\begin{array}{l}\text { Emotional and Behavioral } \\
\text { Disorder }\end{array}$ & IN MN OR RI \\
\hline
\end{tabular}

Only three states included specific language related to how funding could be spent. In Iowa, youth have a "trust account" from which fees for services are distributed. Iowa's statute also articulated a 90-day time limit for foster payments for voluntary placements. Minnesota's statute included kinship assistance related to voluntary placements. In Kentucky, the statute stated that diagnosis, treatment, foster care, day care, care and treatment in a facility, and necessary medical, psychological, and psychiatric care would be paid for by the responsible agency. 


\section{Discussion}

In this review of state statutes, it was clear that there is a wide degree of variation in how states regulate voluntary placement in foster care. On one end of the continuum, Arkansas' statute explicitly stated that it is "not a voluntary placement state." On the other hand, a few statutes, such as in Minnesota, Washington, and California, provided many details about services, processes, and protocols for voluntary placements. Many other statutes allowed for voluntary placements, but did not provide much statutory guidance in how these placements are implemented. States even varied on how they outlined fundamental aspects of voluntary placements including the issue of parents maintaining legal custody and authority of their children. While flexibility at the state-level administration of child welfare policies may be helpful in allowing states to meet unique needs in their communities, it is difficult to assess the outcomes for children and families due to inconsistencies across state and federal policies on voluntary placements. The findings of this statutory analysis of voluntary placements across 50 states and the District of Columbia can help to further this understanding.

\subsection{Implications for Practice, Policy and Research in Child Welfare}

Prior research has indicated that youth who enter care through voluntary placement, rather than court-ordered placements, may also have a higher rate of negative outcomes (Hill, 2017). Although these outcomes may be a reflection that voluntary placements are serving a different population, such as youth with on-going mental health issues that require longer intervention, this prior research also highlights the need to pay closer attention to voluntary placements in child welfare (Hill, 2017). The findings of this current study highlight several potential areas of concern regarding voluntary placements across the United States. One challenge highlighted by this analysis is the lack of clear statutory guidance on voluntary 
placements. Another potential concern is the wide disparities in statutes regarding voluntary placements. Disparate policy implementation might result in disparate outcomes for children and youth.

\subsubsection{Lack of clarity in statutes}

The lack of clarity within the state statutes was evident in this study. Such ambiguity provides significant challenges to consistent and effective implementation of child welfare practices within and across states. Eleven states did not address voluntary placements at all within their statutes, and ten additional statutes only briefly referred to voluntary placements without providing any guidance on implementation. In these states, we identified a lack of clarity around procedures and process of voluntary placements within the statute. Some specific elements that were largely absent from current statutes were in the following areas: providing a clear definition of voluntary foster care placements; outlining specific processes regarding court involvement and mandated timelines in these cases; identifying the legal authority and responsibilities retained by the parents or guardians; and specific guidelines for ending voluntary placements.

Only a few states noted in statute what should be in a service plan for voluntary placements (AZ, CT, OR, FL, HI, MO, RI). Several states, such as Connecticut, outlined very specific requirements for case plans, and other states, like Missouri, outlined specific types of services that might be available through case plans for voluntary placements. Several state descriptions also articulated the agency or department's responsibilities for the child and family as part of the voluntary placement. These included providing placements (AK, IA, MA), care and treatment (AK, GA, IN, KY, NY), casework services and management (GA), paying for services (AK, KY), and providing services (ME, VA). 
One critique of voluntary placements is the lack of oversight and accountability for these placements (GAO, 2003; Gruttadaro, 2014), particularly considering the inconsistencies in reporting and tracking. Two states, Louisiana and Maryland, seemed to address this issue of accountability within statute through the use of a Citizen Review Board and a Local Care Team, respectively. Some states use voluntary placements more to ensure treatment for mental health or access to disability services (GAO, 2003), whereas other states include a continuum of kinship placements that might be considered voluntary placements (Annie E. Casey, 2013). In this analysis, we found similar inconsistencies in language around multiple types of placements. Lack of clarity and guidance in statute reinforces the role of social workers as "street level bureaucrats" (Lipsky, 2010), who have discretion and power in the implementation of policies without consistent accountability and access to needed resources.

\subsubsection{Placement for Treatment}

In the early 2000s there was a concerted advocacy effort on the part of some children's mental health advocates to change state policies around custody relinquishment in cases in which parents were relinquishing their rights solely for the purpose of gaining access to services for their children with emotional, behavioral or mental health disorders (Cohen et al., 1991; Friesen et al, 2003; Giliberti \& Schulzinger, 2000). Advocates identified multiple negative impacts of the practice on children and families including the loss of parental rights, differential implementations of custody practices with families with lower socioeconomic status, harmful effects on parents, children, and family systems, and creating distrust of systems by parents and families (Friesen et al, 2003; McManus \& Friesen, 1989).

Advocacy efforts have successfully changed policies in some states to ensure that parents are not required to relinquish custody in order for their children to receive needed mental health 
or disability-related services (Gruttadaro, 2014). However, Gruttadaro (2014) reported that some parents still needed to transfer legal custody in order to receive these services. This may in part be due to a lack of clarity and consistency in statutory guidelines around voluntary placements, compared with voluntary relinquishment of parental authority. Prior research has noted that children who were voluntarily placed were more likely to have a disability $(41.1 \%)$ compared to court-ordered placements $(27.6 \%)$ (Hill, 2017). Even though accessing adequate treatment for their children may be a primary driver of voluntary placements for parents, the results of this current study found only 11 states specifically addressed disability or mental health related treatment issues in their statutes. Even so, some statutes did provide specific and unique guidelines for voluntary placements that are driven by the need for treatment. For example, states like Minnesota and Connecticut provided more guidance and oversight of voluntary placements as outlined in their statutes, which might serve as a model for other states in providing clearer guidance on these placements. Further research is needed to better understand how states implement voluntary placements focused on treatment and the impact of these placements on children and youth.

\subsubsection{Voluntary Kinship Placements}

Only four states noted specific guidelines around voluntary kinship placements (CA, MN, NY, WA) in this current study. However, it is likely other states also utilize some type of voluntary kin placements, as we know that states often have an entire continuum of kinship arrangements that are utilized by parents and families when looking for alternative care arrangements for their children (Annie E. Casey, 2013; Berrick \& Hernandez, 2016). Since national data on these voluntary placements is not always collected, it is difficult to know the extent to which this occurs, but Annie E. Casey reported estimates that 400,000 families that 
come to the attention of child protection systems are "diverted" to kinship care through the “voluntary" placement of children (Annie E. Casey, 2013).

Even though research does not always distinguish well between the different types of kinship care, there is a significant body of evidence that highlights both the potential benefits and potential concerns with kinship care (Berrick \& Hernandez, 2016; Winokur, Holtan, \& Valentine, 2014). Some studies have found that children in kinship care tend to have more stable placements, continued connections with family and communities, and are better able to preserve racial identities (Berrick, 1997; Koh, 2010; Lin, 2014). However, Vanschoonlandt, Vanderfaeillie, Van Holen, De Maeyer, and Andries (2012) found that youth maintained higher contact with parents when placed with non-kin. Moreover, though data have indicated that children placed in kinship care are less likely to have behavioral troubles, the differences may be explained by selective effects in placement; children with serious behavioral problems may be more likely to be placed with non-kin in the first place (Vanschoonlandt et al., 2012). Additionally, kinship placements have traditionally been underserved, sometimes receiving fewer needed services and financial resources (Berrick \& Hernandez, 2016; Wallace \& Lee, 2013). Policies such as the Fostering Connections to Success and Increasing Adoptions Act of 2008 (Public Law 110-351) have been enacted to increase support to kinship families. Additionally, the increased clarity, reporting, and guidance on voluntary kin placements could continue to increase attention and efforts to ensure children's needs are met and to promote the well-being of children and youth in these placements.

\subsubsection{Disparities in Statutory Guidance.}

Federal statute clearly allows states to access federal, Title IV-E dollars for voluntary placements (up to 180 days), which allows parents the right to seek voluntary, temporary 
assistance to meet the needs of their children. Theoretically, voluntary placement agreements, which are signed by parents and child welfare agencies, could help to outline the specific rights and responsibilities of both parties and outline a plan for services and steps needed to return children safely to their families. State statutes could also ensure that adequate resources and services are provided to the parents, children, and temporary caregivers to meet the needs of the entire family. However, as this statutory analysis suggests, there is wide variability in the details provided at the state-statute level. On one hand, some statutes clearly outlined what should be included in the voluntary placements agreement and provided guidance on service plans and the types of services that families might expect in voluntary placements. On the other hand, many statutes either provided little details about the process for initiating a voluntary placement or did not even permit voluntary placements at all.

In this analysis, another aspect of voluntary placements that varied was the timelines for keeping cases open and timelines related to court review. As noted in the findings, timing of court involvement varied from required at initial placement to no involvement unless a placement reached the 180-day limit. Although some statutes clearly stated that either the child welfare agency or parents could end a voluntary placement, some did not include any description or timeline about the length of potential placements. Further, differing timelines are indicative of a tenuousness to voluntary placements, as they may become court-ordered if a service plan is not completed in the established timeframe within some states. Using the term voluntary in these states has the potential to be misleading. Additionally, unlike court-mandated placements that must adhere to timelines and case review guidelines under the Adoption and Safe Families Act (ASFA), states are not required to follow these guidelines for voluntary placements (Gruttadaro, 2014). One potential concern is that children and youth might be lingering in voluntary 
placements for long periods of time, without achieving permanency or having their needs for services met. At least one study has found that children in voluntary care tended to remain in care longer than children in court-mandated care (Hill, 2017). Again, due to lack of reporting and disparities in how states implement voluntary placements, it is difficult to know precisely the extent to which lingering placements may be a concern, and in which states. Some consistency across statutory regulations of voluntary placements might help ensure that youth are not lingering in care, without needed supportive services.

Several states highlighted specific considerations when working with Indian children in voluntary placement arrangements (CA, MI, MN, OH, WA, WI). Some of these states explicitly noted the need to comply with the Indian Child Welfare Act, while others discussed the role of the Indian tribe in consenting to the voluntary placement. Future research could also explore this area more fully, to ensure the ICWA compliance in these cases. Additionally, questions about youth consent or assent to the voluntary placements could be explored more fully, as this was only noted in four states (except when statutes talked specifically about extended care for 18 year old youth in care).

\subsection{Strengths and Limitations of the Study}

One limitation of the study is that this is an exploratory study providing an initial comparison of how states are addressing voluntary placements in their child welfare systems. However, this initial comparison is important to help inform what is needed for future policy and research, as it is difficult to improve strategies and policies without having a foundational understanding of the topic.

Additionally, coding in a statutory analysis is interpretive, and although some state statutes included very clear guidelines in regards to voluntary placements, some statutes' 
guidelines were vague or incomplete. Having a team of researchers independently coding this data as a way to triangulate the data helped to ensure the reliability of our findings. It is also true that in some instances, there were very general or brief statutes on voluntary placements, but the guidelines were more fully explained in supplemental or administrative materials. In this preliminary analysis, we focused on language reflected in the actual statues, and so we recognize this analysis may not represent all of each states' or D.C.'s efforts and practices in the area of voluntary placements. Our aim was to provide a foundation for further exploration and discussion on this issue.

\section{Conclusion}

This exploratory study aimed to further the understanding of voluntary foster care placements, a topic on which there has been very little research and attention. Removing children from their biological families is a serious, and often traumatic, experience for children and youth, even if this process is a voluntary choice of the parents or caregivers. Through this statutory analysis, we have outlined general observations about both common and unique characteristics among state statutes, as well as highlighting what is currently absent in statutory guidance on voluntary placements. More exploration is needed to further understand how statutes affect child welfare practices and, ultimately, how these policies impact children and families across states and D.C. For instance, youth decision-making was only noted in a few statutes, and so future research could more fully explore the extent to which the youth themselves have a voice in determining the need for voluntary placement.

Additionally, the wide disparities in length of voluntary placement across states begs the question as to whether the needs, circumstances, and experiences of these children are also widely divergent. Future studies might explore the reasons states use voluntary placements, and 
examine if states vary their use of these placements for different groups of children. Moreover, additional research is needed to determine what happens if voluntary placements reach their time limit, and how many of these voluntary placements become mandatory court-ordered placements. Future research could also examine other guidance that might be provided at the state level via handbooks or administrative manuals. The lack of clarity in statutes on voluntary placements needs further attention by child welfare administrators and policy-makers, in order to ensure the on-going safety, permanency, and well-being of children in these voluntary arrangements. 


\section{References}

Annie E. Casey. (2013). The kinship diversion debate: Policy and practice implications for children, families and child welfare agencies. Retrieved from http://www.aecf.org/m/pdf/KinshipDiversionDebate.pdf

Bass, S., Shields, M. K., \& Behrman, R. E. (2004). Children, families, and foster care: Analysis and recommendations. The Future of Children, 14(1), 5-29.

Benner, K. (2009). Legalized orphans: Parental relinquishment to child welfare. University of Missouri-Columbia.

Berrick, J. D. (1997). Assessing quality of care in kinship and foster family care. Family Relations, 273-280.

Berrick, J. D., \& Hernandez, J. (2016). Developing consistent and transparent kinship care policy and practice: State mandated, mediated, and independent care. Children and Youth Services Review, 68, 24-33.

Bringewatt, E. H., \& Gershoff, E. T. (2010). Falling through the cracks: Gaps and barriers in the mental health system for America's disadvantaged children. Children and Youth Services Review, 32(10), 1291-1299.

Bromley, B. E., \& Blacher, J. (1991). Parental reasons for out-of-home placement of children with severe handicaps. Mental Retardation, 29(5), 275-280.

Child Welfare Information Gateway. (2017). Extension of foster care beyond age 18. Washington, D.C: Children's Bureau. Retrieved from https://www.childwelfare.gov/pubPDFs/extensionfc.pdf

Cohen, R., Harris, R., Gottlieb, S., \& Best, A. M. (1991). States' use of transfer of custody as a 
requirement for providing services to emotionally disturbed children. Psychiatric Services, 42(5), 526-530.

Cohen, R., Preiser, L., Gottlieb, S., Harris, R., Baker, J., \& Sonenklar, N. (1993). Relinquishing custody as a requisite for receiving services for children with serious emotional disorders: A review. Law and Human Behavior, 17(1), 121-134.

Crettenden, A., Wright, A., \& Beilby, E. (2014). Supporting families: Outcomes of placement in voluntary out-of-home care for children and young people with disabilities and their families. Children and Youth Services Review, 39, 57-64.

Cuddeback, G. S. (2004). Kinship family foster care: A methodological and substantive synthesis of research. Children and Youth Services Review, 26(7), 623-639.

Dworetzkey, B. (2013). Medicaid and children with special health care needs/disabilities: An overview. Catalyst Center. http://cahpp.org/resources/fact-sheet-medicaid-and-childrenwith-special-health-care-needsdisabilities-an-overview/?

Friesen, B. J., Giliberti, M., Katz-Leavy, J., Osher, T., \& Pullmann, M. D. (2003). Research in the service of policy change: The "custody problem." Journal of Emotional and Behavioral Disorders, 11(1), 39-47.

German, M. L., \& Maisto, A. A. (1982). The relationship of a perceived family support system to the institutional placement of mentally retarded children. Education and Training of the Mentally Retarded, 17-23.

Giliberti, M., \& Schulzinger, R. (2000). Relinquishing custody: The tragic result of failure to meet children's mental health needs. Bazelon Center for Mental Health Law.

Gilbert, N. (2012). A comparative study of child welfare systems: Abstract orientations and concrete results. Children and Youth Services Review, 34(3), 532-536. 
Gleeson, J. P., Wesley, J. M., Ellis, R., Seryak, C., Talley, G. W., \& Robinson, J. (2009). Becoming involved in raising a relative's child: Reasons, caregiver motivations and pathways to informal kinship care. Child and Family Social Work, 14(3), 300-310.

Gruttadaro, D. (2014). The tragedy of custody relinquishment. National Alliance on Mental Illness. Retrieved from http://www.sanmateo.networkofcare.org/mh/library/article.aspx?id=445

Hill, K. (2017). Prevalence, experiences, and characteristics of children and youth who enter foster care through voluntary placement agreements. Children and Youth Services Review, 74, 62-70.

Hsieh, H. \& Shannon, S. (2005). Three approaches to qualitative content analysis. Qualitative Health Research, 15(9), 1277-1288.

Jones, L. (1998). The social and family correlates of successful reunification of children in foster care. Children and Youth Services Review, 20(4), 305-323.

Koh, E. (2010). Permanency outcomes of children in kinship and non-kinship foster care: Testing the external validity of kinship effects. Children and Youth Services Review, 32(3), 389-398.

Lee, J. S., Courtney, M. E., \& Tajima, E. (2014). Extended foster care support during the transition to adulthood: Effect on the risk of arrest. Children and Youth Services Review, 42, 34-42.

Lightfoot, E., Hill, K, \& LaLiberte, T. (2010). Disability statutes in the termination of parental rights and other child custody statutes. Child Abuse and Neglect, 34,927-934.

Lin, C. H. (2014). Evaluating services for kinship care families: A systematic review. Children and Youth Services Review, 36, 32-41. 
Lipsky, M. (2010). Street level bureaucracy: dilemmas of individuals in public services $30^{\text {th }}$ edition). New York: Russel Sage Foundation.

McConnell, D., Savage, A., \& Breitkreuz, R. (2014). Resilience in families raising children with disabilities and behavior problems. Research in Developmental Disabilities, 35(4), 833848.

McLean, B., \& Thomas, R. (1996). Informal and formal kinship care populations: A study in contrasts. Child Welfare, 75(5), 489-505.

McManus, M. C., \& Friesen, B. J. (1989). Barriers to accessing services: Relinquishing legal custody as a means of obtaining services for children with serious emotional disabilities. Focal Point, 3(3), 1-5.

Mechanic, D., McAlpine, D., \& Rochefort, D. (2014). Mental health and social policy: Beyond managed care ( $6^{\text {th }}$ ed). Boston: Pearson.

Miles, M. \& Huberman, A.M. (1994). Qualitative data analysis: An expanded sourcebook (2 ${ }^{\text {nd }}$ ed). Thousand Oaks, CA: Sage.

Nankervis, K., Rosewarne, A., \& Vassos, M. (2011a). Respite and parental relinquishment of care: A comprehensive review of the available literature. Journal of Policy and Practice in Intellectual Disabilities, 8(3), 150-162.

Nankervis, K., Rosewarne, A., \& Vassos, M. (2011b). Why do families relinquish care? An investigation of the factors that lead to relinquishment into out-of-home respite care. Journal of Intellectual Disability Research, 55(4), 422-433.

National Alliance on Mental Illness Minnesota (2009). Keeping families together: A guide for families to understand intensive treatment options for children with mental illnesses. St. Paul, MN: Author. 
Rosenzweig, J. \& Brennan, E. (2008). Work, life, and the mental health system of care. Baltimore, MD: Paul Brookes Publishing Co.

Sanger, C. (2006). Infant safe haven laws: Legislating in the culture of life. Columbia Law Review, 106(4) 753-829.

Sliva, S. \& Lambert, C. (2015). Restorative justice legislation in the American states: A statutory analysis of emerging legal doctrine. Journal of Policy Practice, 14(2), 77-95.

Social Security Act of 1935, 42 U.S.C., $§ \S 671-679 b(2010)$.

United States General Accounting Office. (2003). Child welfare and juvenile justice: Federal agencies could play a stronger role in helping states reduce the number of children placed solely to obtain mental health services. GAO-03-397. Washington, DC: Author.

Vanschoonlandt, F., Vanderfaeillie, J., Van Holen, F., De Maeyer, S., \& Andries, C. (2012). Kinship and non-kinship foster care: Differences in contact with parents and foster child's mental health problems. Children and Youth Services Review, 34(8), 1533-1539.

Vericker, T., Kuehn, D., \& Capps, R. (2007). Latino children of immigrants in the Texas child welfare system. Protecting Children, 22(2), 20-40.

Wallace, G. W., \& Lee, E. (2013). Diversion and kinship care: A collaborative approach between child welfare services and NYS's Kinship Navigator. Journal of Family Social Work, 16(5), 418-430.

Winokur, M., Holtan, A., \& Valentine, D. (2009). Kinship care for the safety, permanency, and well-being of children removed from the home for maltreatment. In M. Winokur (Ed.), Cochrane Database of Systematic Reviews. Chichester, UK: John Wiley \& Sons, Ltd. https://doi.org/10.1002/14651858.CD006546.pub2 